\title{
EDITORIAL
}

\section{CPD and recertification: improving patient outcomes through focused learning}

\author{
J. S. Bamrah \& Dinesh Bhugra
}

\begin{abstract}
J. S. Bamrah is a Consultant
Psychiatrist at North Manchester General Hospital and Chair of the Royal College of Psychiatrists' Continuing Professional Development Committee. Dinesh Bhugra is Professor of Mental Health and Cultural Diversity at the Institute of Psychiatry, London, and President of the Royal College of Psychiatrists. Correspondence Dr J.S. Bamrah, Park House, North Manchester General Hospital, Crumpsall, Manchester M8 5RB, UK. Email: jsbamrah@aol.com
\end{abstract}

\section{SUMMARY \\ The impending regulatory changes for all medical professionals in the UK will make it necessary for doctors to be relicensed and, in the case of specialists, to be recertified. This editorial argues strongly in favour of recertification and proposes that continuing professional development is one of the main planks on which recertification of psychiatrists should be based. We present cogent reasons for this, as well as evidence that improved learning contributes positively to healthcare. We also recommend that psychiatrists should make learning objectives more clinically focused as well as properly resourced. \\ DECLARATION OF INTEREST \\ J.S.B. is Director of CPD and D.B. is President of the Royal College of Psychiatrists.}

Continuing professional development (CPD) is a life-long process that involves enhancing one's knowledge, acquiring new skills and polishing up existing ones. For doctors, as for other professionals, the learning experience starts at an early age. It is inevitable that in careers that might span 30 years, each of us will be exposed to a large variety of clinical situations and learning methods. In the case of psychiatrists, this means that there is often a need not only to keep up with basic medical knowledge, but also to learn to achieve more refined skills in specific areas of expertise and practice. Although CPD is necessarily an individual exercise, the involvement of doctors in well-structured learning

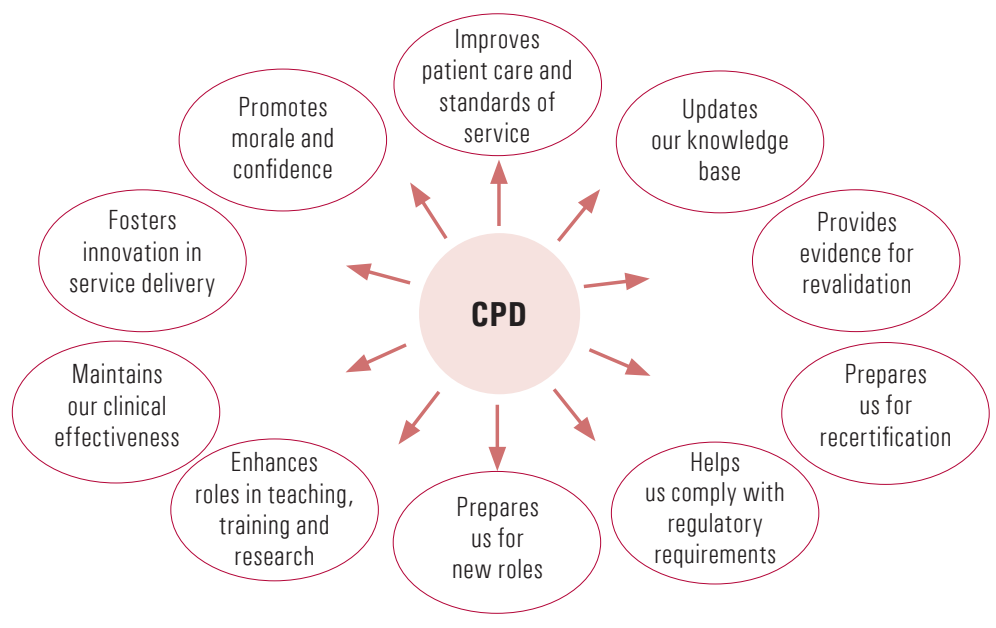

The benefits of CPD. programmes has indirect benefits for patients, carers and employing organisations. The Department of Health (1998) has recommended that for CPD to be more effective, it needs to be more robustly managed.

This editorial sets out the importance of CPD in the context of training, skills gained, knowledge acquired and enhancement of medical practice. Quantitative data on the subject are sparse, but there has been sufficient research in the different aspects of medicine to demonstrate the effect and effectiveness of CPD (Davis 1992, 1995, Grant 1998). Our primary focus is the impending proposal for recertification, although there is no reason why more general conclusions might not be drawn by doctors who work in psychiatry, but are not specialists as defined by the General Medical Council (GMC).

The Royal College of Psychiatrists is responsible for setting standards for psychiatric practice (Royal College of Psychiatrists 2004). It also aims to provide the framework that will enable its Members, Fellows andAffiliates to fulfil their CPD requirements (Royal College of Psychiatrists 2001). Continuing professional development is essential for psychiatric consultants, associate specialists, staff-grade doctors and specialty doctors, all of whom are required to register their $\mathrm{CPD}$ portfolios with the College in order to gain an annual certificate of 'good standing'. Although the College makes no assertions that CPD makes us good doctors, there is no doubt that education and training help us to achieve better standards of patient care and raise morale in general (Fig. 1). Continuing professional development has been advocated as essential to recertification and ongoing competency (Bashook 1998), and the Chief Medical Officer for England's working group on medical revalidation has stated that "participation in CPD will be an important means for doctors to demonstrate their fitness to practice' (Department of Health 2008: p. 24).

\section{Specialist registration and certification \\ The specialist register}

The specialist register was created in 1997 to separate specialists from other medical practitioners. Among the 56 specialties created, psychiatry was 
subdivided further into general adult psychiatry (with endorsements in liaison, rehabilitation and substance misuse psychiatry), child and adolescent psychiatry, old age psychiatry, psychiatry of learning disability, forensic psychiatry and psychotherapy.

\section{Certification}

In the UK, certification is the only method of gaining specialist registration, which is necessary for taking up a consultant post. Certification can be acquired by presenting either a Certificate of Completion of Specialist Training (CCST) or, for doctors trained overseas, a Certificate of Eligibility for Specialist Registration (CESR) (www.pmetb. org.uk/index.php?id=cesr).

The CCST was established in 1997, replacing the Certificate of Completion Training (CCT), as part of the Calman reforms to make training more seamless. In 2005, after the establishment of Modernising Medical Careers (MMC), further change took place to shorten the overall period of training before attaining a CCST. In 2007, more radical changes under the auspices of the Postgraduate Medical Examination and Training Board, have led to controversial streamlining of training, establishing two post-registration foundation years, three years of basic specialist training and a further three years of higher specialist training. The durations of basic and of higher specialist training are indicative: some trainees will need less time and some more to achieve the required competencies. However, there is no likelihood of these changes embedding, as the Tooke review (2008) and the Parliamentary Health Committee reports (House of Commons Health Committee 2008) have challenged them.

\section{Skills acquisition in specialist training}

During the course of training, doctors in the UK have to demonstrate that they have acquired the necessary skills to become specialist psychiatrists by successfully passing the College's membership examinations (the MRCPsych) as well as satisfying their trainers of their competence. Competency is judged on objective workplace-based assessments and 360 degree appraisal and is assessed at the annual review of competence progression.

\section{Clinical benefits of certification}

Research evidence from the USA supports the notion that specialist training has a positive effect on patients' health outcomes. In surgery, certification had a high correlation with reduced mortality (Prystowsky 2002). In patients treated for acute myocardial infarction, certified doctors provided better overall quality of care and prescribed fewer inappropriate drugs than non-certified doctors (Norcini 2002; Chen 2006). Certified doctors were also less likely to have faced medical disciplinary action than their non-certified counterparts. In one study of 890 disciplined doctors matched with nondisciplined controls, non-certified doctors were more likely to be disciplined for negligence (38\%), unprofessional conduct (10\%) or inappropriate prescribing (9\%) (Kohatsu 2004). Another study established a strong link in this group of doctors with use of drugs or alcohol (Clay 2003).

\section{Post-certification}

The extensive testing and examinations during specialist training are barely matched by systematic assessments of performance during the course of specialist careers. Although all psychiatrists practising in the UK are required to engage in CPD activities, many of the types of learning involved have not been evaluated. An early review of randomised controlled trials of $\mathrm{CPD}$ activities showed no single learning method to be superior to another (Davis 1995), but a later, more extensive analysis found that interactive CPD, not didactic lecture-based sessions, was more likely to change physicians' performance (Davis 1999). In the 1995 study, the authors concluded that CPD is most effective if it is delivered in a managed environment, a finding very similar to that of the Department of Health (1998). They also recommended that the individual must have a clear reason for undertaking a particular CPD activity. A demonstration of the use of CPD in everyday practice reinforces learning behaviour and disseminates the importance of CPD among colleagues and in the organisation. They found that CPD was more likely to be effective if three conditions were met: learning was linked to practice, educational activity was linked to personal incentive rather than outside influences, and the educational event was followed by reinforcing activities or situations.

\section{The plateau in medical learning}

Despite the early gains doctors seem to make in acquiring the basic skills necessary to treat patients, most professionals are content to continue at an average level of performance for reasons that are illunderstood. Some have suggested that the thresholds of optimum performance are set by each individual's personal qualities such as abilities, mental capacity and innate talents (Ericsson 2004). Others have argued that the performance of physicians can be raised by self-directed learning (Mazmanian 2002) and evaluation of the knowledge and skills gained through learning experiences (Davis 1992). In one review, 62 out of 63 studies showed that physicians' performance declined over time (Choudhry 2005), making focused learning all the more important in medical practice. 


\section{Recertification}

Under the proposals laid out by the Chief Medical Officer for England, revalidation, which has been through a lengthy gestation, will require two strands of GMC approval for specialists: relicensing (or relicensure, an unfortunate term with connotations of 'censure') and recertification. Revalidation is principally to ensure that doctors update their knowledge and skills, and remain fit to practise. All practising doctors registered with the GMC will be required to renew their license annually through annual appraisal by a trained appraiser (usually their medical manager). For recertification, they will have to meet standards for specialist practice determined by the medical Royal Colleges and approved by the GMC (Department of Health 2008).

To make the process less bureaucratic, the GMC aims to deliver its commitment of 'one process (of submission of information, appraisal, 360 degree feedback, good standing for CPD, etc.), two outcomes (relicensing and recertification)' rather than 'two processes, two outcomes' (Fig. 2).

\section{Why implement recertification?}

The arguments in favour of recertification have been made cogently (Catto 2008). Although doctors in the UK on the whole continue to enjoy the trust and respect of their patients and the general public, in many countries patients and the public demand proof of continuing medical competence (Eismont 2002). In the USA, certificates for specialist psychiatric practice were first introduced by the American Board of Psychiatry and Neurology for child and adolescent psychiatry in 1959 (Juul 2004). In 1995, the status of US specialist registration changed: 10-year, time-limited certificates were issued, but the process of recertification in the sub-specialties of child and adolescent, geriatric, addiction and forensic psychiatry, and in the less popular subspecialties of clinical neurophysiology and pain medicine, has been based on passing multiple choice questions (MCQs) and computer-based supervised tests. Pass rates are high (over 95\%) and there is no compulsion for specialists to be recertified.

\begin{tabular}{|c|c|c|c|c|c|c|}
\hline \multicolumn{7}{|c|}{ Revalidation } \\
\hline \multicolumn{5}{|c|}{ Recertification } & \multicolumn{2}{|c|}{ Relicensing } \\
\hline $\begin{array}{l}\text { 'Good } \\
\text { standing' } \\
\text { for CPD }\end{array}$ & $\begin{array}{c}\text { Multisource } \\
\text { feedback }\end{array}$ & $\begin{array}{c}\text { Audit, } \\
\text { research, } \\
\text { teaching, } \\
\text { outcomes }\end{array}$ & Appraisal & \begin{tabular}{|c} 
Miscellaneous, \\
e.g. service \\
accredita- \\
tion, critical \\
incidents
\end{tabular} & $\begin{array}{c}\text { Basic } \\
\text { medical } \\
\text { skills }\end{array}$ & $\begin{array}{c}\text { Good } \\
\text { medical } \\
\text { practice }\end{array}$ \\
\hline
\end{tabular}

\section{How to assess competence}

The rigours of revalidation and the expectations that patients have of both the GMC and doctors themselves (Bandaranayake 1994; Lockyer 2004) have generated much interest in doctors' performance and the qualitative tools required to assess this. A review commissioned by the Department of Health in the wake of the Shipman Inquiry (Smith 2004) found that among the high-risk organisations of the aviation, nuclear and offshore industries, assessments of competency were carried out against defined standards of competence, that the interval between assessments ranged from 6 months to 3 years, and that repeated failure was an exception rather than the rule (Flinn 2005). Costs are high: in the aviation industry, with far fewer pilots than there are doctors, the annual budget for safety regulation amounts to $£ 70$ million.

To make recertification in medicine credible, the medical profession needs to use reliable, evidencebased and valid instruments to assess competence. These must be backed up by educational events that promote skills-based learning. There is limited evidence that knowledge-based tests improve clinical performance, although anecdotally patients like the notion that doctors should be required to sit them. However, there are sufficient data to suggest that doctors' clinical performance is enhanced by reflecting on their professional development and setting out learning objectives supported by methods of achieving them (Campbell 1999; Epstein 2002). The Royal College of Psychiatrists recommends that this exercise be performed in peer groups, although there are no studies showing their effectiveness. An audit of 100 personal development plan summaries revealed that most of the College's $\mathrm{CPD}$ registrants participate in peer groups and carry out objectives setting, but the importance of these activities has yet to be evaluated (details available from the authors).

\section{How can CPD help recertification?}

\section{What makes an expert?}

During the early, formative years of medical training, learning is very much based on acquiring theoretical knowledge and on the model of serving as an apprentice. After they gain their consultancy, however, there is a fundamental shift in how doctors learn. The emphasis is more on self-directed acquisition of content knowledge and on reflective learning, with the drawback that these can be purely subjective. A major criticism of lecture-based learning in continuing medical education is that it cannot be individually tailored, and what is taught may not be relevant to clinical practice (Davis 1999). 
One desired effect of the training programme for doctors is the time required to gain the experience to become experts. ${ }^{\dagger}$ Some researchers consider 10 years of experience in a particular field to be a reliable indicator of expertise, whereas others have concluded that experience alone does not inevitably produce experts (Ericsson 2004). One study showing the benefits of experience underpinned by training compared the accuracy of diagnosis of heart sounds by cardiologists and by general practitioners. The cardiologists had greatest diagnostic accuracy, and the accuracy of general practitioners was directly proportional to the length of time since graduation from medical school (Butterworth 1960). A decline in age-related diagnostic performance is heavily mitigated by active engagement in CPD, particularly in areas relevant to clinical practice; CPD also improves the results of recertification examinations (Rhodes 2003).

\section{Maintaining and enhancing expertise}

Continuing professional development is not, and should not be, just a number-crunching exercise in which participants to CPD schemes such as that run by the College (www.psychiatrycpd.co.uk/default. aspx) simply try to accumulate the necessary 50 hours a year in order to gain a certificate (Bouch 2003). To be effective and fully represent the learning experience of psychiatrists, i.e. 'learning on the job', CPD needs to take into account the content of the educational activity, the knowledge gained, skills imparted and experience accumulated. Targeted CPD - learning aimed at enhancing knowledge and skills in a particular sphere of practice - can modify behaviour through a variety of activities (Pyatt 1997). It seems rational, therefore, to organise CPD in such a way that objectives are set prospectively, others are added as the year progresses and any objectives that have not been achieved, for whatever reason, are carried over to the subsequent cycle.

The College has an arbitrary rule requiring a certain balance of 'external' and 'internal' CPD learning (Royal College of Psychiatrists 2001: p. 19), but with trust and health board sizes increasing, and many participants undertaking more external CPD, this rule is applied flexibly. Undertaking external CPD activity has the benefit of ensuring that psychiatrists do not become too insular in their own departments, and that their learning is not just a product of local directives and government targets.

There is no doubt that some amount of group learning is essential for all doctors, but equally there is a place for individuals gaining knowledge on their own.
Although the type of work-based learning recommended in adult learning theory is encouraged in some quarters, regardless of whether or not it is of value to doctors (Grant 1998), there seems little doubt that the increasing reliance on web-based learning is appropriate. So that the College keeps in step, the CPD Committee has agreed that up to 10 hours of web-based learning can count towards the 50 hour annual requirement. It recommends a balance of CPD activity, with reading being such a core part of a doctors' work that it need not be formally recorded.

One real benefit of focusing on CPD is that it can encapsulate both professional growth for the doctor and the needs of the health service (Fig. 3). However, the scientific evaluation of the attitudes and behaviours of evidence-based practice is complex and not as straightforward as evaluating knowledge and skills (Davis 2006).

\section{Peer-group involvement}

In order that CPD incorporates a good balance of learning objectives, the College recommends that all participants join a peer group. This works better for psychiatrists working in managed organisations than for those who are either retired and return to practise or are working in single-handed private practices. The extent to which peer groups function well depends on the members' commitment to the task. The peer group should be objective and supportive, but not confrontational. This should set the scene for a frank discussion of each individual's learning objectives, the pathway to achieving each objective and the issues of time and resources required to achieve these goals. Thinking about one's CPD should not be regarded as an annual formality: mid-point and year-end reviews of progress with peers would iron out any difficulties that arise in the pursuit of learning objectives and CPD credits.

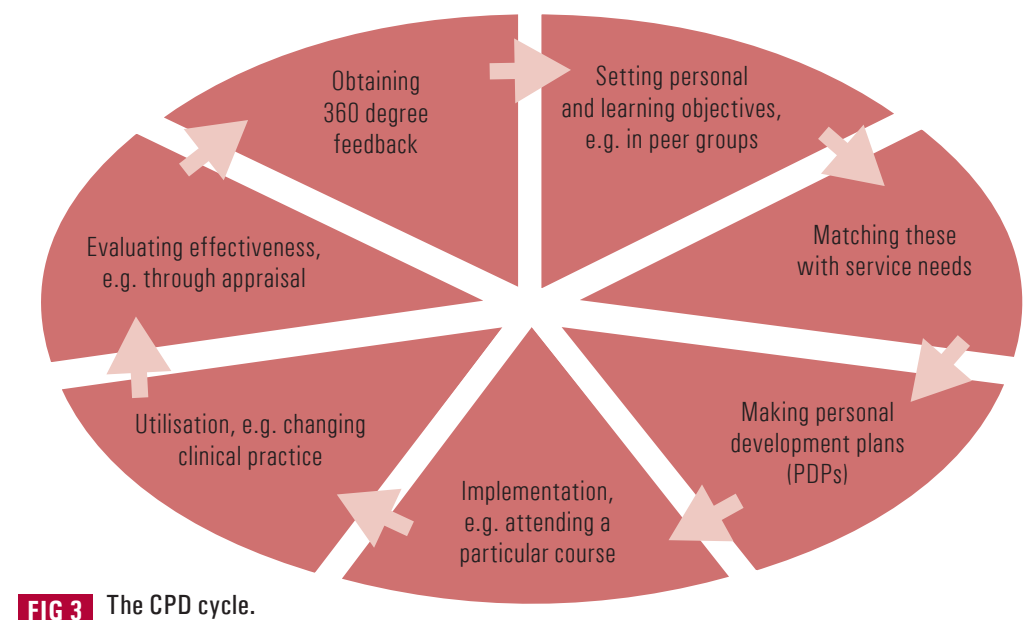

${ }^{\dagger}$ For a discussion of what makes an expert, see Bhugra D (2008) Deliberate practice and CPD in psychiatry. Advances in Psychiatric Treatment; 14: 161-2. Ed. 


\section{Conclusions}

Continuing professional development has a clear role to play in maintaining professional standards (Bourdillon 1999). The literature confirms its importance in the professional development of doctors, which leads us to conclude that CPD must form the bedrock of whatever shape recertification takes. On the one hand, recertification puts CPD firmly on the government's agenda, with the spinoff that it would have to be properly resourced in terms of time and funds. On the other, it risks being very open, thus taking ownership away from the individual. Undoubtedly, for CPD to be effective, psychiatrists must continue developing prospective learning objectives that incorporate their aspirations of high-level education and training with the best possible clinical standards of care for patients and that are open to fair scrutiny by their peers.

\section{Acknowledgements}

We are grateful to Sir Graeme Catto, President of the GMC, for helpful comments and advice.

\section{References}

Bandaranayake R (1994) Maintenance of competence and/or recertification: policy considerations. In The Certification and Recertification of Doctors: Issues in the Assessment of Clinical Competence (eds D Newble, B Jolly, R Wakeford). Cambridge University Press.

Bashook PG, Parboosingh J (1998) Continuing medical education: recertification and the maintenance of competence. BMJ; 316: 545-8.

Bouch J (2003) Continuous professional development for psychiatrists: CPD and regulation. Advances in Psychiatric Treatment; 9: 81-3.

Bourdillon P, du Boulay C, Heard S, et al (1999) The Good CPD Guide. A Practical Guide to Managed CPD. Joint Centre for Education in Medicine, Reed Healthcare.

Butterworth JS, Reppert EH (1960) Auscultatory acumen in the general medical population. JAMA; 174: 32-4.

Campbell CM, Parboosingh J, Gondocz T, et al (1999) Study of the factors influencing stimulus to learning recorded by physicians keeping a learning portfolio. Journal of Continuing Education in the Health Professions; 19: 16-24.

Catto G (2008) Relicensing, recertification and regulation. Advances in Psychiatric Treatment; 14: 1-2.

Chen J, Rathore SS, Wang Y, et al (2006) Physician board certification and the care and outcomes of elderly patients with acute myocardial infarction. Journal of General Internal Medicine; 21: 238-44.

Choudhry NK, Fletcher RH, Soumerai SH (2005) Systematic review: the relationship between clinical experience and quality of health care. Annals of Internal Medicine; 142: 260-73.

Clay SW, Conatser RR (2003) Characteristics of physicians disciplined by the State Medical Board of Ohio. Journal of American Osteopathic Association; 103: 81-8.

Davis DA, Thomson MA, Oxman AD, et al (1992) Evidence for the effectiveness of CME. A review of 50 randomised controlled trials. JAMA; 268: 1111-7.

Davis DA, Thomson MA, Oxman AD, et al (1995) Changing physician performance: a systematic review of the effect of continuing medical education strategies. JAMA; 274: $700-5$.

Davis D, O'Brien MAT, Freemantle N, et al (1999) Impact of formal continuing medical education. Do conferences, workshops, rounds, and other traditional continuing education activities change physician behaviour or health care outcomes? JAMA; 282: 867-74.

Davis DA, Mazmanian PE, Fordis M, et al (2006) Accuracy of physician selfassessment compared with observed measures of competence. A systematic review. JAMA; 296: 1094-102.

Department of Health (1998) A First Class Service: Quality in the New NHS. TSO (The Stationery Office).

Department of Health (2008) Medical Revalidation - Principles and Next Steps: The Report of the Chief Medical Officer for England's Working Group. TSO IThe Stationery Office).

Eismont FJ, Anderson S, Cruess RL, et al (2002) Orthopaedic recertification. Journal of Bone and Joint Surgery; 84: 1069-77.

Epstein RM, Hundert EM (2002) Defining and assessing professional competence. JAMA; 287: 226-35.

Ericsson KA (2004) Deliberate practice and the acquisition and maintenance of expert performance in medicine and related domains. Academic Medicine; 79 (issue 10 suppll): $\$$ 70-81.

Flinn R (2005) Safe in their Hands? Licensing and Competence Assurance for Safety-critical Roles in High Risk Industries. A Report for the Department of Health. University of Aberdeen.

Grant J, Stanton F (1998) The Effectiveness of Continuing Professional Development. A Report for the Chief Medical Officer's Review of CPD in Practice (2nd edn). Joint Centre for Education in Medicine.

House of Commons Health Committee (2008) Modernising Medical Careers. Third Report of Session 2007-08. Vol. I: Report, together with Formal Minutes. TSO IThe Stationery Office) (http://www.parliament.the-stationery-office.com/pa/cm200708/ cmselect/cmhealth/25/25i.pdf).

Juul D, Scheiber SC, Kramer TAM (2004) Sub-specialty certification by the American Board of Psychiatry and Neurology. Academic Psychiatry; 28: 12-7.

Kohatsu ND, Gould D, Ross LK (2004) Characteristics associated with physician discipline. A case-control study. Archives of Internal Medicine; 164: 653-8.

Lockyer JM, Violato C (2004) An examination of the appropriateness of using a common peer assessment instrument to assess physician skills across specialties. Academic Medicine: 79 (issue 10 suppll): S5-8.

Mazmanian PE, Davis DA (2002) Continuing medical education and the physician as a learner. Guide to the evidence. JAMA; 288: 1057-60.

Norcini JJ, Lipner RS, Kimball HR (2002) Certifying examination performance and patient outcomes following acute medical infarction. Medical Education; 36: $853-9$

Prystowsky JB, Bordage G, Feinglass JM (2002) Patient outcomes for segmental colon resection according to surgeon's training, certification and experience. Surgery; 132: 663-70.

Pyatt RS, Moore DE, Caldwell SC (1997) Improving outcomes through innovative continuing medical education partnership. Journal of Continuing Education in the Professions; 17: 239-44.

Rhodes RS, Biesten TW, Ritchie WP, et al (2003) Continuing medical education activity and American Board of Surgery Examination performance. Journal of the American College of Surgeons; 196: 604-9.

Royal College of Psychiatrists (2001) Good Psychiatric Practice: CPD ICouncil Report CR90). Royal College of Psychiatrists (http://www.rcpsych.ac.uk/publications/college reports/cr/cr90.aspx).

Royal College of Psychiatrists (2004) Good Psychiatric Practice (2nd edn) (Council report CR125). Royal College of Psychiatrists (http://www.rcpsych.ac.uk/ publications/collegereports/cr/cr125.aspx).

Smith J (2004) Safeguarding Patients: Lessons from the Past - Proposals for the Future. Shipman Inquiry: Fifth Report. TSO (The Stationery Office).

Tooke J (2008) Aspiring to Excellence. Findings and Recommendations of the Independent Inquiry into Modernising Medical Careers. Universities UK Ihttp:// www.mmcinquiry.org.uk/Final 8 Jan 08 MMC all.pdf). 